\title{
Fertility preservation for patients with gynecologic malignancies: The Korean Society for Fertility Preservation clinical guidelines
}

\author{
Sanghoon Lee', Seul Ki Kim², Kyung Joo Hwang ${ }^{3}$, Tak Kim', Seok Hyun Kim ${ }^{4}$ \\ 'Department of Obstetrics and Gynecology, Korea University College of Medicine, Seoul; ${ }^{2}$ Department of Obstetrics and Gynecology, Seoul National \\ University Bundang Hospital, Seongnam; ${ }^{3}$ Department of Obstetrics and Gynecology, Ajou University School of Medicine, Suwon; ${ }^{*}$ Department of \\ Obstetrics and Gynecology, Seoul National University College of Medicine, Seoul, Korea
}

Fertility preservation plays a central role in cancer care since an increasingly large number of cancer patients are surviving as a result of improvements in diagnostic and therapeutic strategies. Physicians who take part in the initial diagnosis and management of gynecologic cancer should understand the importance of fertility preservation. Since indications for fertility preservation are limited to early-stage gynecologic cancer, a surgeon must carefully consider each indication. Before performing fertility-sparing surgery, health professionals should compare its oncologic and pregnancy outcomes with those of other standard treatments. Individualized treatment strategies should be delivered depending on the patient's situation, and physicians should provide timely information and appropriate counseling.

Keywords: Fertility preservation; Fertility-sparing surgery; Gynecologic cancer; Pregnancy

\section{Introduction}

Standard guidelines for fertility preservation were first proposed in 2006 by the American Society of Clinical Oncology. Those guidelines recommended using gonadal shielding during radiotherapy to reduce the radiation doses delivered to reproductive organs and applying ovarian transposition (oophoropexy), in which ovaries are surgically displaced to avoid radiation damage, as standard methods of treatment. Trachelectomy, in which only the cervix is removed, and other conservative surgical treatments that avoid surgical removal of the ovaries are standard treatments for cervical and gynecologic can-

Received: Feb 27, 2017 · Revised: Mar 20, 2017 · Accepted: Jul 5, 2017 Corresponding author: Kyung Joo Hwang

Department of Obstetrics and Gynecology, Ajou University School of Medicine, 206 World cup-ro, Yeongtong-gu, Suwon 16499, Korea

Tel: +82-31-219-5249 Fax:+82-31-219-5245 E-mail:kjhwang74@daum.net

*This study was supported by the National Research Foundation of Korea Grant funded by the Korean Government (No. NRF-2016R1C1B3015250).

This is an Open Access article distributed under the terms of the Creative Commons Attribution Non-Commercial License (http://creativecommons.org/licenses/by-nc/4.0/) which permits unrestricted non-commercial use, distribution, and reproduction in any medium, provided the original work is properly cited. cer [1].

In 2012, the National Comprehensive Cancer Network (NCCN) proposed guidelines for adolescent and young adult oncology, which recommended that young patients aged 15 to 39 years with cancer be sufficiently informed about fertility preservation and the risk of infertility as a result of cancer treatment [2]. The present study reviews the methods of fertility preservation for patients with different types of gynecologic cancer: cervical cancer, ovarian cancer, and endometrial cancer.

\section{Options for fertility preservation in gynecologic malignancies}

\section{Cervical cancer}

According to the statistics reported by the National Cancer Registration and Statistics System, in 2012, 3,857 people developed cervical cancer, and cervical cancer was the seventh most common type of cancer among women in Korea. Of those affected by cervical cancer, 1,235 were younger than 46 years, and one-third of all cases of cervical cancer occurred among women of childbearing age [3]. 
As mentioned in the introduction, ovarian transposition is a standard practice for patients with cervical cancer who wish to preserve their fertility. In cases of locally confined cervical cancer, it is important to transpose the ovaries above the upper border of the target radiation field. In general, the upper border of the radiation field is defined as the upper border of the L4/L5 lumbar vertebra. During standard ovarian transposition, the ovaries should be surgically moved to above the anterior superior iliac spine or up to the navel to prevent them from undergoing radiation damage $[4,5]$.

Conization and trachelectomy are standard methods of fertility preservation for patients with early-stage cervical cancer. The indica-

Table 1. Indications for trachelectomy in cervical cancer

$$
\text { Indication }
$$

1. Women who desire to preserve fertility (aged $<40-45$ years)

2. Stage IA $1^{\text {a) }}$ (with lymph vascular space involvement), IA2, IB1

3. Lesion size $\leq 2 \mathrm{~cm}$

4. Histologically squamous, adeno, or adenosquamous carcinoma

5. No upper cervical canal involvement of cancer

6. No evidence of lymph node metastasis

${ }^{a}$ Conization: IA1 without lymphovascular space invasion. tions for trachelectomy are presented in Table 1 [4]. Cervical conization can be performed for stage IA1 or IA2 cervical cancer. The indications for fertility-sparing surgery in cervical cancer proposed by the NCCN guidelines are listed in Table 2 [6].

The oncologic outcomes and obstetric outcomes of trachelectomy are as follows. In the combined results of multiple studies, the rate of recurrent cervical cancer was 3.5\% (22 of 619) and that of mortality was $1.9 \%$ (12 of 619) in a total of 619 patients with cervical cancer who underwent trachelectomy. Among the 619 patients, 236 patients successfully became pregnant, but $20 \%$ of these patients had a miscarriage in the first trimester, and $8 \%$ (20 of 236) had a miscarriage in the second trimester. Eventually, $66 \%$ of the pregnant patients had a delivery in the third trimester (157 of 236), 15\% before the 32 nd week of pregnancy and $85 \%$ after the 32nd week of pregnancy [7-11].

If a patient has a cervical tumor larger than $2 \mathrm{~cm}$, trachelectomy may be preceded by neoadjuvant chemotherapy, which is performed to reduce the size of the tumor. In a study that investigated the oncologic outcomes of neoadjuvant chemotherapy followed by trachelectomy in 54 patients, a complete or partial response was observed in $81.5 \%$ of the patients (44 of 54 ); recurrence occurred in

Table 2. Fertility-sparing surgery in cervical cancer

\begin{tabular}{ll}
\hline Stage & \multicolumn{1}{c}{ Treatment } \\
\hline Stage IA1 (no lymphovascular space invasion) & Cone biopsy with negative margins (preferably a nonfragmented specimen with 3-mm negative margins) \\
Stage IA1 (with lymphovascular space & $\begin{array}{c}\text { Cone biopsy with negative margins (preferably a nonfragmented specimen with 3-mm negative margins)+ } \\
\text { invasion) and stage IA2 }\end{array}$ \\
& $\begin{array}{l}\text { pelvic lymph node dissection+/-para-aortic lymph node sampling or radical trachelectomy+pelvic lymph } \\
\text { node dissection+/-para-aortic lymph node sampling }\end{array}$ \\
Ragical trachelectomy+pelvic lymph node dissection+/-para-aortic lymph node sampling
\end{tabular}

Tumors with small cell neuroendocrine histologic findings and adenoma malignum are not considered suitable tumors for this procedure.

${ }^{a}$ Fertility-sparing surgery for stage IB1 has been most thoroughly validated for tumors $\leq 2 \mathrm{~cm}$.

Table 3. Oncologic and fertility outcomes for six different fertility-sparing surgical procedures in cervical cancer

\begin{tabular}{|c|c|c|c|c|c|c|}
\hline \multirow{2}{*}{ Variable } & \multirow{2}{*}{$\begin{array}{l}\text { Dargent's } \\
\text { procedure }\end{array}$} & \multirow{2}{*}{$\begin{array}{l}\text { Simple trachelectomy } \\
\text { or cone resection }\end{array}$} & \multirow{2}{*}{$\begin{array}{c}\text { Neoadjuvant } \\
\text { chemotherapy and } \\
\text { conservative surgery }\end{array}$} & \multicolumn{3}{|c|}{ Abdominal radical trachelectomy } \\
\hline & & & & Laparotomic & Laparoscopic & Robot-assisted \\
\hline \multicolumn{7}{|l|}{ Series and case reports } \\
\hline No. of series or case reports & 21 & 13 & 17 & 28 & 18 & 9 \\
\hline No. of patients & 1,523 & 242 & 114 & 866 & 252 & 101 \\
\hline Patients excluded & 159 & 12 & 15 & 206 & 14 & 12 \\
\hline \multicolumn{7}{|l|}{ Oncologic outcome } \\
\hline Recurrent disease & 58 & 4 & 6 or 7 & 31 & 15 & 2 \\
\hline Died from disease & 24 & 0 & 2 & 9 & 3 & 0 \\
\hline \multicolumn{7}{|l|}{ Fertility outcome } \\
\hline Pregnancy & 487 & 105 & 54 & 175 & 55 & 20 \\
\hline Fetal loss (trimester 1 or 2 ) & 103 & 15 & 11 & 37 & 16 & 2 \\
\hline Preterm delivery & 104 & 13 & 11 & 21 & 19 & 5 \\
\hline Pregnancy rate $(\mathrm{n}, \%)^{\mathrm{a})}$ & $216 / 343(63)$ & $15 / 26(57)$ & $27 / 39(69)$ & $114 / 235(49)$ & $25 / 52(48)$ & $17 / 21(81)$ \\
\hline
\end{tabular}

Adapted from Bentivegna et al. Lancet Oncol 2016;17:e240-53, with permission of Elsevier [13].

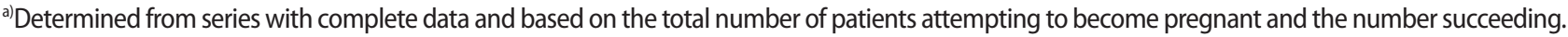


three patients; and 28 patients successfully became pregnant [12]. In a recent systemic review, six different techniques of trachelectomy were assessed in terms of oncologic and pregnancy outcomes (Table 3). The authors recommended that fertility preservation techniques should be selected based on the experience of the team, discussion with the patient or couple, and objective oncologic data to balance the best choice for a cure with the optimum fertility results $[13,14]$.

\section{Ovarian cancer}

Ovarian cancer can be categorized as benign, borderline, and malignant tumors. Since conservative surgery is performed in most women of childbearing age with benign tumors, we would like to focus our discussion on borderline and malignant tumors.

\section{1) Borderline tumors}

Borderline tumors have excellent prognoses. For stage 1 ovarian cancer, the 15 -year survival rate is $98 \%$. Even with all cancer stages included, the 5 -year survival rate of borderline ovarian cancer is $86 \%$ to $90 \%$ (American Cancer Society, National Cancer Institute, SEER [Surveillance, Epidemiology, and End Results] data 2004 to 2010). In a meta-analysis that included 39 studies and a total of 5,105 patients who underwent conservative surgery for borderline tumors, the rate of recurrence was lower for patients who underwent unilateral salpingo-oophorectomy than for those who underwent ovarian cystectomy. However, no significant difference in the survival rate was found between the two groups of patients [15].

The NCCN guidelines also recommend that unilateral salpingo-oophorectomy preserving the uterus and contralateral ovary can be considered for patients with apparent early-stage invasive epithelial tumors or low malignant potential lesions who wish to preserve their fertility. Chemotherapy is not recommended because it has no known benefits in the treatment of borderline tumors.

Studies have reported no difference in the pregnancy rates between patients who have a single ovary after undergoing unilateral salpingo-oophorectomy and those with two ovaries. However, differences in the length of pregnancy between these groups have been reported [16].

\section{2) Malignant tumors}

Epithelial ovarian cancer represents $80 \%$ of all malignant ovarian tumors and is the most common type of ovarian cancer. Surgical staging and/or cytoreductive surgery followed by adjuvant chemotherapy are performed as the primary treatment of ovarian cancer. The complete surgical staging includes peritoneal and pelvic washing cytology, total hysterectomy, bilateral salpingo-oophorectomy, omentectomy, pelvic/para-aortic lymphadenectomy, and multiple peritoneal biopsies.
According to the clinical practice guidelines for gynecologic cancer published by the Korean Gynecologic Oncology Group, patients who exhibit stage IA or IC cancer based on surgical findings, and who wish to become pregnant in the future, can undergo fertility-preserving surgery, in conjunction with comprehensive surgical staging, regardless of the cancer grade [17-20].

Comprehensive surgical staging is a replacement procedure for complete surgical staging, and it includes preservation of the uterus and an ovary at the operating surgeon's discretion, as well as a thorough gross and broad histological examination of all intraperitoneal and retroperitoneal organs. The NCCN guidelines recommend chemotherapy for stage IC cancer regardless of the cancer grade, as well as for stage IA or IB cancer with grade 3 tumors or clear cell adenocarcinoma [21]. Using a stricter standard, some studies have recommended that stage IA or IB and grade 1 or 2 cancer be used as an appropriate indication for fertility preservation [22,23]. Park et al. [24] investigated the oncologic safety and reproductive outcomes of fertility-preserving surgery in patients with epithelial ovarian cancer in Korea, and reported low survival rates for patients with cancer at higher than stage IC or at grade 3 , and concluded that stage IA-C and grade 1-2 cancer can be safely treated with fertility preservation. Regarding germ cell tumors and sex-cord stromal cell tumors, stage IA/IB dysgerminomas, stage IA grade 1 immature teratomas, and stage IA embryonal or yolk sac tumors can be monitored clinically without the use of chemotherapy for fertility preservation.

Ovarian carcinosarcoma is a rare type of cancer, and has a poor prognosis according to the NCCN guidelines. Fertility preservation treatment is not recommended regardless of the patient's age [21].

\section{Endometrial cancer}

Endometrial cancer is the most common gynecologic malignancy in Western countries, and it has steadily increasing recently in Korea. Approximately $3 \%$ to $14 \%$ of endometrial cancer cases are diagnosed in premenopausal women 40 years of age or younger who want to preserve their fertility [25-29].

Table 4. Criteria for considering fertility-sparing options in the management of endometrial cancer

Criteria

1. Well-differentiated (grade 1) endometrioid adenocarcinoma on dilation and curettage confirmed by expert pathology review

2. Disease limited to the endometrium on magnetic resonance imaging (preferred) or transvaginal ultrasound

3. Absence of suspicious or metastatic disease on imaging

4. No contraindications to medical therapy or pregnancy

5. Patients should undergo counselling that the fertility-sparing option is not standard of care for the treatment of endometrial cancer.

All criteria must be met. 
According to clinical practice guidelines for gynecologic cancer, total hysterectomy, bilateral salpingo oophorectomy, pelvic/para-aortic lymphadenectomy, and pelvic/peritoneal washing cytology are performed as the standard primary procedures for the surgical staging of endometrial cancer [30]. The NCCN guidelines advise that fertility preservation be considered only when all the following conditions are met (Table 4) [31].

Fertility-preserving surgery can be performed when there is no invasion into the myometrium by stage I grade 1 endometrial cancer. For patients who satisfy all the aforementioned conditions, the use of megestrol, medroxyprogesterone, or a levonorgestrel intrauterine device (IUD) can be considered for continuous progestin-based therapy. According to the literature, the appropriate dose of megestrol is $40-400 \mathrm{mg} /$ day, and that of medroxyprogesterone is $200-800 \mathrm{mg} /$ day [32-34]. Following continuous progestin-based therapy, endometrial sampling, either through dilation and curettage or endometrial biopsy, must be performed every 3-6 months to assess treatment outcomes. Patients who had an IUD inserted may experience discomfort during IUD replacement at each assessment. If a patient shows complete remission 6 months later, she may attempt to get pregnant while being carefully monitored every 3-6 months, and undergo surgical staging surgery, including total hysterectomy and/ or bilateral salpingo-oophorectomy, upon pregnancy completion.

Oophorectomy is commonly performed in premenopausal women with endometrial cancer; however, many studies found that ovarian preservation had no effect on the overall survival of young patients with early-stage endometrial cancer. Ovarian preservation is likely to be safe and not associated with an increase in cancer-related mortal-

Table 5. Summary of fertility-sparing options in gynecologic malignancies

\begin{tabular}{lcc}
\hline Diagnosis & \multicolumn{1}{c}{ Indication } \\
\hline Cervical cancer & $\begin{array}{c}\text { Stage IA1 } \\
\text { (no lymphovascular space invasion) }\end{array}$ & Conization
\end{tabular}

Fertility option

Comment

(no lymphovascular space invasion)

Preferably a nonfragmented specimen with 3-mm negative margins

- If positive margins are found, repeat conization or perform trachelectomy.

Small cell neuroendocrine tumor and adenoma malignum are not considered for this procedure.

Stage IA1 (with lymphovascular space invasion) and stage IA2

Stage IB1
Conization+pelvic lymph node dissection - Sentinel lymph node mapping can be +/-para-aortic lymph node sampling or considered. trachelectomy+pelvic lymph node dissection+/-para-aortic lymph node sampling

Trachelectomy+pelvic lymph node dissection+/- para-aortic lymph node sampling

Unilateral salpingo-oophorectomy

Ovarian cancer

Borderline tumor FIGO stage I

Epithelial cancer FIGO stage I, grades 1-2

Malignant germ cell and sex cord stromal cell tumors

Endometrial cancer Stage IA, grade 1 (endometrioid adenocarcinoma, no myometrial invasion) $2 \mathrm{~cm}$ in size, trachelectomy may be
Continuous progestin-based hormonal therapy (megestrol, medroxyprogesterone, or levonorgestrel IUD)
- Fertility-sparing surgery for stage IB1 has been most validated for tumors $\leq 2 \mathrm{~cm}$. - If a patient has a cervical tumor larger than preceded by neoadjuvant chemotherapy.

- Unilateral salpingo-oophorectomy preserving the uterus and contralateral ovary can be considered for patients with apparent early-stage invasive epithelial tumors or low malignant potential lesions for patients who wish to preserve their fertility.

- Endometrial sampling (either D\&C or endometrial biopsy) must be performed every 3-6 months to assess treatment outcomes.

- If a patient shows complete remission 6 months later, she may attempt to get pregnant while being carefully monitored every 3-6 months.

- Surgical staging surgery including total hysterectomy and/or bilateral salpingooophorectomy should be considered upon pregnancy completion. 
ity [35-37].

If the patient does not become pregnant during the monitoring period and develops new or recurrent endometrial cancer, she must consider undergoing surgical staging surgery. If endometrial cancer is detected within 6-9 months after the completion of the aforementioned medical therapies and the assessment of treatment outcomes, surgical staging surgery must again be considered.

In regard to the oncologic and pregnancy outcomes of fertilitysparing therapies, a systematic review and meta-analysis performed by Gallos et al. [38] found the regression rate of endometrial cancer to be $76.2 \%$, the relapse rate to be $40.5 \%$, and the live birth rate to be $28 \%$ following fertility-preserving surgery.

\section{Conclusion}

Fertility-sparing options in the treatment of gynecologic malignancies are summarized in Table 5. Health professionals must discuss the risk of early menopause and infertility with patients of childbearing age and their families. Before performing fertility-preserving surgery, health professionals should compare its oncologic and pregnancy outcomes with those of other standard treatments. In addition, since indications for fertility preservation are limited to early-stage gynecologic cancer, a surgeon must carefully consider each indication and be aware that fertility-preserving surgery should be performed only when treatment options are limited to conservative treatment or pharmacotherapy.

\section{Conflict of interest}

No potential conflict of interest relevant to this article was reported.

\section{References}

1. Lee SJ, Schover LR, Partridge AH, Patrizio P, Wallace WH, Hagerty $\mathrm{K}$, et al. American Society of Clinical Oncology recommendations on fertility preservation in cancer patients. J Clin Oncol 2006;24:2917-31.

2. National Comprehensive Cancer Network. Adolescent and Young Adult (AYA) Oncology version 2.2017: NCCN clinical practice guidelines in oncology (NCCN guidelines) [Internet]. Fort Washington: National Comprehensive Cancer Network; 2017 [cited 2017 Aug 14]. Available from: https://www.nccn.org/professionals.

3. National Cancer Center. Annual report of cancer statistics in Korea in 2012. Sejong: Ministry of Health and Welfare; 2014.

4. Lee S, Song JY, Ku SY, Kim SH, Kim T. Fertility preservation in women with cancer. Clin Exp Reprod Med 2012;39:46-51.
5. Hwang JH, Yoo HJ, Park SH, Lim MC, Seo SS, Kang S, et al. Association between the location of transposed ovary and ovarian function in patients with uterine cervical cancer treated with (postoperative or primary) pelvic radiotherapy. Fertil Steril 2012; 97:1387-93.e1-2.

6. National Comprehensive Cancer Network. Cervical cancer version 1.2017: NCCN clinical practice guidelines in oncology (NCCN guidelines) [Internet]. Fort Washington: National Comprehensive Cancer Network; 2016 [cited 2017 Aug 14]. Available from: https://www.nccn.org/professionals.

7. Plante M, Gregoire J, Renaud MC, Roy M. The vaginal radical trachelectomy: an update of a series of 125 cases and 106 pregnancies. Gynecol Oncol 2011;121:290-7.

8. Willows K, Lennox G, Covens A. Fertility-sparing management in cervical cancer: balancing oncologic outcomes with reproductive success. Gynecol Oncol Res Pract 2016;3:9.

9. Shepherd JH, Spencer C, Herod J, Ind TE. Radical vaginal trachelectomy as a fertility-sparing procedure in women with earlystage cervical cancer-cumulative pregnancy rate in a series of 123 women. BJOG 2006;113:719-24.

10. Hertel H, Kohler C, Grund D, Hillemanns P, Possover M, Michels W, et al. Radical vaginal trachelectomy (RVT) combined with laparoscopic pelvic lymphadenectomy: prospective multicenter study of 100 patients with early cervical cancer. Gynecol Oncol 2006;103:506-11.

11. Mathevet $P$, Laszlo de Kaszon E, Dargent D. Fertility preservation in early cervical cancer. Gynecol Obstet Fertil 2003;31:706-12.

12. Wang D, Yang J, Shen K, Xiang Y. Neoadjuvant chemotherapy followed by fertility-sparing surgery for women with stage IB1 cervical cancer. J Gynecol Oncol 2013;24:287-90.

13. Bentivegna E, Gouy S, Maulard A, Chargari C, Leary A, Morice P. Oncological outcomes after fertility-sparing surgery for cervical cancer: a systematic review. Lancet Oncol 2016;17:e240-53.

14. Bentivegna E, Maulard A, Pautier P, Chargari C, Gouy S, Morice P. Fertility results and pregnancy outcomes after conservative treatment of cervical cancer: a systematic review of the literature. Fertil Steril 2016;106:1195-211.e5.

15. Vasconcelos I, de Sousa Mendes M. Conservative surgery in ovarian borderline tumours: a meta-analysis with emphasis on recurrence risk. Eur J Cancer 2015;51:620-31.

16. Lass A. The fertility potential of women with a single ovary. Hum Reprod Update 1999;5:546-50.

17. Korean Society of Gynecologic Oncology. Practice guideline for ovarian cancer version 3.0 [Internet]. Seoul: Korean Society of Gynecologic Oncology; 2015 [cited 2017 Aug 14]. Available from: http://www.sgo.or.kr.

18. Schlaerth AC, Chi DS, Poynor EA, Barakat RR, Brown CL. Long- 
term survival after fertility-sparing surgery for epithelial ovarian cancer. Int J Gynecol Cancer 2009;19:1 199-204.

19. Kajiyama H, Shibata K, Mizuno M, Nawa A, Mizuno K, Matsuzawa $\mathrm{K}$, et al. Fertility-sparing surgery in young women with mucinous adenocarcinoma of the ovary. Gynecol Oncol 2011;122: 334-8.

20. Ditto A, Martinelli F, Lorusso D, Haeusler E, Carcangiu M, Raspagliesi F. Fertility sparing surgery in early stage epithelial ovarian cancer. J Gynecol Oncol 2014;25:320-7.

21. National Comprehensive Cancer Network. Ovarian cancer including fallopian tube cancer and primary peritoneal cancer version I 2016: NCCN clinical practice guidelines in oncology (NCCN guidelines) [Internet]. Fort Washington: National Comprehensive Cancer Network; 2016 [cited 2017 Aug 14]. Available from: https://www.nccn.org/professionals.

22. Satoh T, Hatae M, Watanabe Y, Yaegashi N, Ishiko O, Kodama S, et al. Outcomes of fertility-sparing surgery for stage I epithelial ovarian cancer: a proposal for patient selection. J Clin Oncol 2010;28:1727-32.

23. Fruscio R, Ceppi L, Corso S, Galli F, Dell'Anna T, Dell'Orto F, et al. Long-term results of fertility-sparing treatment compared with standard radical surgery for early-stage epithelial ovarian cancer. Br J Cancer 2016;115:641-8.

24. Park JY, Kim DY, Suh DS, Kim JH, Kim YM, Kim YT, et al. Outcomes of fertility-sparing surgery for invasive epithelial ovarian cancer: oncologic safety and reproductive outcomes. Gynecol Oncol 2008;110:345-53.

25. Lee SW, Lee TS, Hong DG, No JH, Park DC, Bae JM, et al. Practice guidelines for management of uterine corpus cancer in Korea: a Korean Society of Gynecologic Oncology Consensus Statement. J Gynecol Oncol 2017;28:e12.

26. Siegel R, Naishadham D, Jemal A. Cancer statistics, 2013. CA Cancer J Clin 2013;63:11-30.

27. Crissman JD, Azoury RS, Barnes AE, Schellhas HF. Endometrial carcinoma in women 40 years of age or younger. Obstet Gynecol 1981;57:699-704.

28. Park JY, Nam JH. Progestins in the fertility-sparing treatment and retreatment of patients with primary and recurrent endometrial cancer. Oncologist 2015;20:270-8.
29. Gallup DG, Stock RJ. Adenocarcinoma of the endometrium in women 40 years of age or younger. Obstet Gynecol 1984;64: 417-20.

30. Korean Society of Gynecologic Oncology. Practice guideline for uterine corpus cancer version 3.0 [Internet]. Seoul: Korean Society of Gynecologic Oncology; 2015 [cited 2017 Aug 14]. Available from: http://www.sgo.or.kr.

31. National Comprehensive Cancer Network. Uterine neoplasms version 1.2017: NCCN clinical practice guidelines in oncology (NCCN guidelines) [Internet]. Fort Washington: National Comprehensive Cancer Network; 2016 [cited 2017 Aug 14]. Available from: https://www.nccn.org/professionals.

32. Ramirez PT, Frumovitz M, Bodurka DC, Sun CC, Levenback C. Hormonal therapy for the management of grade 1 endometrial adenocarcinoma: a literature review. Gynecol Oncol 2004;95: 133-8.

33. Tangjitgamol S, Manusirivithaya S, Hanprasertpong J. Fertilitysparing in endometrial cancer. Gynecol Obstet Invest 2009;67: 250-68.

34. Erkanli S, Ayhan A. Fertility-sparing therapy in young women with endometrial cancer: 2010 update. Int J Gynecol Cancer 2010;20:1170-87.

35. SGO Clinical Practice Endometrial Cancer Working Group, Burke WM, Orr J, Leitao M, Salom E, Gehrig P, et al. Endometrial cancer: a review and current management strategies. Part II. Gynecol Oncol 2014;134:393-402.

36. Sun C, Chen G, Yang Z, Jiang J, Yang X, Li N, et al. Safety of ovarian preservation in young patients with early-stage endometrial cancer: a retrospective study and meta-analysis. Fertil Steril 2013;100:782-7.

37. Wright JD, Buck AM, Shah M, Burke WM, Schiff PB, Herzog TJ. Safety of ovarian preservation in premenopausal women with endometrial cancer. J Clin Oncol 2009;27:1214-9.

38. Gallos ID, Yap J, Rajkhowa M, Luesley DM, Coomarasamy A, Gupta JK. Regression, relapse, and live birth rates with fertility-sparing therapy for endometrial cancer and atypical complex endometrial hyperplasia: a systematic review and metaanalysis. Am J Obstet Gynecol 2012;207:266.e1-12. 